\title{
DETERMINATION OF THE ZONE ENDANGERED BY METHANE EXPLOSION IN GOAF WITH CAVING OF LONGWALLS VENTILATED ON „Y” SYSTEM
}

\author{
Jarosław BRODNY, Magdalena TUTAK \\ Silesian University of Technology
}

\begin{abstract}
:
One of the most dangerous and most commonly present risks in hard coal mines is methane hazard. During exploitation by longwall system with caving, methane is emitted to mine heading from the mined coal and coal left in a pile. A large amount of methane also flows from neighboring seams through cracks and fissures formed in rock mass. In a case of accumulation of explosive methane concentration in goaf zone and with appropriate oxygen concentration and occurrence of initials (e.g. spark or endogenous fire), it may come to the explosion of this gas. In the paper there are presented results of numerical analysis of mixture of air and methane streams flow through the real heading system of a mine, characterized by high methane hazard. The aim of the studies was to analyze the ventilation system of considered heading system and determination of braking zones in goaf zone, in which dangerous and explosive concertation of methane can occur with sufficient oxygen concentration equal to at least $12 \%$. Determination of position of these zones is necessary for the selection of appropriate parameters of the ventilation system to ensure safety of the crew. Analysis of the scale of methane hazard allows to select such a ventilation system of exploitation and neighboring headings that ensures chemical composition of mining atmosphere required by regulation, and required efficiency of methane drainage. The obtained results clearly show that numerical methods, combined with the results of tests in real conditions can be successfully used for the analysis of variants of processes related to ventilation of underground mining, and also in the analysis of emergency states.
\end{abstract}

Key words: methane hazard, goaf with caving, CFD, ANSYS Fluent

\section{INTRODUCTION}

Underground exploitation of hard coal is very dangerous due to many natural hazards [2]. One of the most common and most dangerous natural hazards is methane hazard, which is connected to possibility of inflammation and/or explosion of methane mixed with air.

In the years 2005-2015 in Polish coal mines 31 hazardous events associated with methane hazard took place (inflammation and explosions of methane), in which 59 people died and 114 were injured [4].

The most common place of occurrence of these events are areas of the exploitation longwalls. This result from the fact that in Poland the exploitation of hard coal usually is conducted in wall system with caving roof rock, and coal seams are characterized by high methane content.

The largest amount of methane is emitted during mining of coal from exposed body of coal. Slightly less amount of methane is released into the mining headings from the gobs. The source of this methane is coal remained in the gobs and methane flowing out from the overtaken and undertaken seams through cracks and fissures presented in the rock mass.

Methane is an explosive gas. Most often boundaries of explosive mixtures of methane, air and inert gases are described by the so-called. Coward triangle explosion [6]. Within the limits of the occurrence of the concentration of explosive methane explosion initials may be endogenous fire, blasting or sparks arising from friction of moving lumps of rock.

Very significant meaning for assessment of methane hazard degree in the region of performed exploitation has knowledge of the location of zones with explosive concentration of methane in goaf zone. This knowledge constitutes the basis for carrying out preventive actions in order to reduce its concentration.

Therefore it becomes reasonable to perform works in order to determine zones of increased methane concentration (together with concentration in explosive range) in the goaf with caving simultaneously taking into account a possibility of occurrence minimum $12 \%$ of oxygen concentration in the air flow in such zone. The simultaneous fulfilment of these conditions causes that such zone is particularly endangered to the possibility of a methane explosion.

Determination of such zones on the base of tests in real conditions is practically impossible. For this reason it is necessary to use other research methods, which enable to determine parameters of gases filling goaf with caving at any point of these gobs. Such possibilities create model studies based on the numerical simulations.

These simulations is a widely applied research tool $[3,5$, $10]$, which more common is used in many areas of science including variant analyses of processes associated with the outflow of gases in mining headings and in the analyses of faults, and for such should be admitted an occurrence of 
explosive concentration of methane in underground working environment.

In recently years, more and more widely for the analysis of ventilation problems related to the control of mining atmosphere composition in the mining headings and in gobs treated as porous medium, numerical methods are used $[3,7,8,9]$.

In this article are presented the analysis results, which the aim was to determinate the zone of explosive methane gas in goaf with caving longwalls ventilated on " $Y$ " system (known in the literature as a system or type). For calculations ANSYS Fluent software based on finite volume method, which enable very precisely to determine the physical and chemical air and methane mixture parameters at any point of tested mining heading and goaf with caving was used. Such precisely determination of these parameters on the base of the test in real conditions is practically impossible.

\section{MATHEMATICAL MODEL OF FLOW}

Numerical fluid mechanics (CFD) is a method of simulations of phenomena related to flow of liquids and gases, heat and mass transfer, as well as chemical reactions [11].

In the paper this method was used to determine the physical and chemical parameters of the mixture of air and methane, flowing through the real system of mine excavations.

A turbulent flow of viscous incompressible fluid (in this case a gas), was described by the Navier-Stokes system of equations, which together with continuity equation makes a complete system of relationships, allowing to determine pressure and field of flow velocity [11].

Issues connected with transport of fluid are solved basing in the following fluid mechanics equations [1]: The continuity equation:

$$
\frac{\partial \rho}{\partial t}+\frac{\partial(\rho u)}{\partial x}+\frac{\partial(\rho v)}{\partial y}+\frac{\partial(\rho w)}{\partial z}=0
$$

where:

$\mathrm{u}, \mathrm{v}, \mathrm{w}$ - directions velocity, $\mathrm{m} / \mathrm{s}$,

$\rho$ - density, $\mathrm{kg} / \mathrm{m}^{3}$,

$\mathrm{t}$ - time, $\mathrm{s}$.

The momentum equation:

$$
\frac{\partial}{\partial t}(\rho v)+\nabla \cdot(v v)=-\nabla p+\nabla \tau+\rho g+F
$$

where:

$\mathrm{p}$ - static pressure, $\mathrm{Pa}$,

$\tau$ - the stress tensor, $\mathrm{Pa}$,

$\mathrm{g}$ - the gravitational body force, $\mathrm{m} / \mathrm{s}^{2}$,

$\mathrm{F}$ - the external body force, $\mathrm{N}$.

The basis of the mathematical description of the transport process of the methane emission to the headings is a mass conservation principle related to this gas. Mathematical model of the transport, being a system of equations of advection-diffusion, which for i-th substance it takes the following form:

The species transport equation:

$$
\frac{\partial}{\partial t}\left(\rho Y_{i}\right)+\nabla \cdot\left(\rho v Y_{i}\right)=-\nabla \cdot J_{i}+R_{i}+S_{i}
$$

where:

$\mathrm{v}$ - velocity, $\mathrm{m} / \mathrm{s}$,

$Y_{i}$ - the local mass fraction of each species,

$\mathrm{J}_{\mathrm{i}}$ - the diffusion flux of species $\mathrm{i}, \mathrm{kg} /\left(\mathrm{m}^{2} \mathrm{~s}\right)$,

$\mathrm{R}_{\mathrm{i}}$ - the net rate of production of species $\mathrm{i}$ by chemical reaction,

$\mathrm{S}_{\mathrm{i}}$ - the rate of creation by addition from the dispersed phase plus any user-defined sources.

The mass duffusion in turbulent flows - Fick's law:

$$
J_{i}=-\left(\rho D_{i, m}+\frac{\mu_{t}}{S c_{t}}\right) \nabla Y_{i}
$$

where:

$D_{i, m}$ - the mass diffusion coefficient for species $i$ in the mixture, $\mathrm{m}^{2} / \mathrm{s}$,

$\mu$ - the viscosity, Pa.s,

$\mathrm{Sc}_{\mathrm{t}}$ - the turbulent Schmidt number, 0.7.

Presented mathematical model of the flow connects description of air flow and transport of gases.

\section{THE MODEL OF FLOW}

Goaf zone of exploitation longwall B-11 in seam 358/1 together with adjacent headings included into IV category of methane hazard were subjected to flow analysis.

The aim of the analysis was to determine in goaf with caving zones with explosive concentration of methane at minimum $12 \%$ concentration of oxygen in the air flowing through these goaf. The exact boundaries of the triangle shows the Coward explosive triangles for methane (Fig. 1).

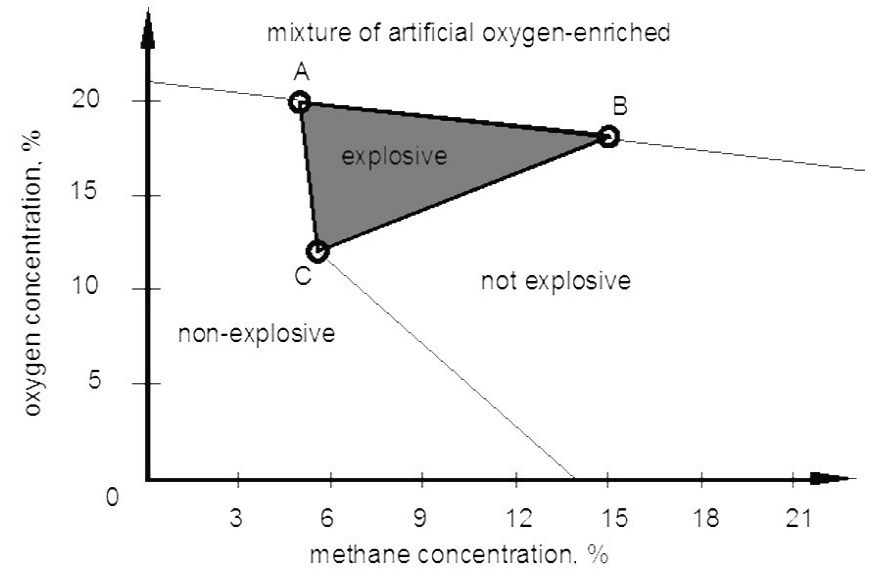

Fig. 1 Coward explosive triangles for methane

Characteristics of geological-mining conditions of the longwall B-11 in seam 358/1

The longwall B-11 in exploitation seam 358/1 is a longitudinal system with caving roof in the direction from boundary and its mining parameters are equaled:

- length of the longwall $250.0 \mathrm{~m}$,

- height of the longwall $1220.0 \mathrm{~m}$,

- transverse slope $\quad 2^{\circ}$,

- longitudinal slope $\quad 4^{\circ}$

This longwall was ventilated in "Y" system.

In a Figure 2 there is presented scheme of wall ventilation with indicated line of air distribution.

To the maingate B-11 average $1119 \mathrm{~m}^{3} / \mathrm{min}$ of air was supplied and to the tailgate B-10 average $1029 \mathrm{~m}^{3} / \mathrm{min}$ of air was supplied. Release of methane to the exploitation longwall amounted average to $5.4 \mathrm{~m}^{3} / \mathrm{min}$, and mean value 
of its concentration at inlet from the tailgate amounted to $0.64 \%$.

Modeling tests of the airflow through goaf with caving of this longwall was performed for its length amounted to $435 \mathrm{~m}$.

Tailgate B-10 in seam 358/1

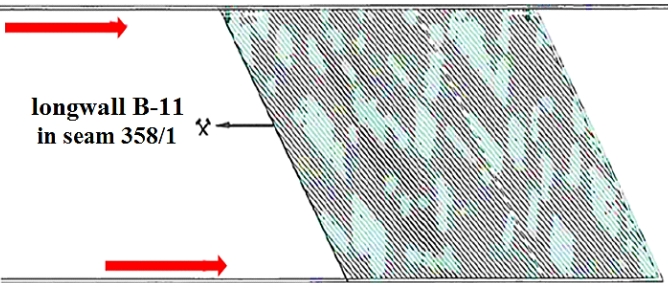

Maingate B-11 in seam 358/1

\section{Fig. 2 The longwall ventilation scheme}

\section{The analysis results}

In order to perform the analysis, a geometrical model of goaf with caving and exploitation longwall and longwall headings was developed (Fig. 3). The vertical extent of airflow in goaf with caving amounted to 3.5 times of the height of exploiting seam (9.8 m).

Boundary conditions necessary to perform the numerical calculations, were selected basing on the real measurements of physical and chemical parameters of steam air supplied to the longwall and absolute methane content of the longwall.

For the presented system of headings fresh air flows by longwall gates to crossing with exploitation longwall, then changes direction of flow by 90 degrees and flows through the longwall, and then again changes the angle of movement by 90 degree and flows out to the tailgate.

As an "inlet" type boundary condition, a constant velocity field of air was assumed. In inlet cross-section for analyzed heading a uniform distribution of the velocity in longwall gates was applied.

For analyzed model, exit type of boundary condition was defined as an "outlet", whereas walls were defined as impermeable, which surface roughness corresponded to the height of $0.2 \mathrm{~m}$, and its temperature (treated as temperature of the surrounding rock mass) amounted to $305^{\circ} \mathrm{K}$. Calculations were made for pressure, which reference value amounted to $111945 \mathrm{~Pa}$.

It was assumed, that goaf with caving create isotropic porous medium with different permeability, created with shale and sandstone. The oxygen part in the air stream supplied to the longwall equals to $21 \%$.

In Figure 4, there is presented distribution of methane concentration in goaf with caving in exploitation longwall, and in Figure 5 - distribution of oxygen concentration in goaf with caving.

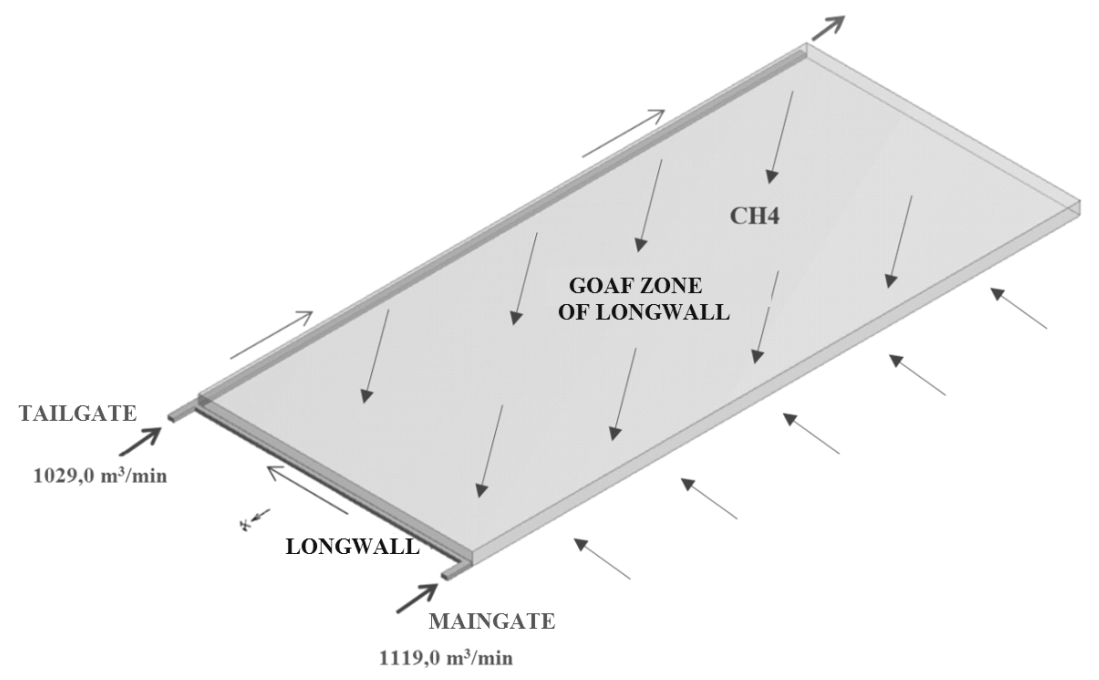

Fig. 3 Geometrical model of investigated system of excavations

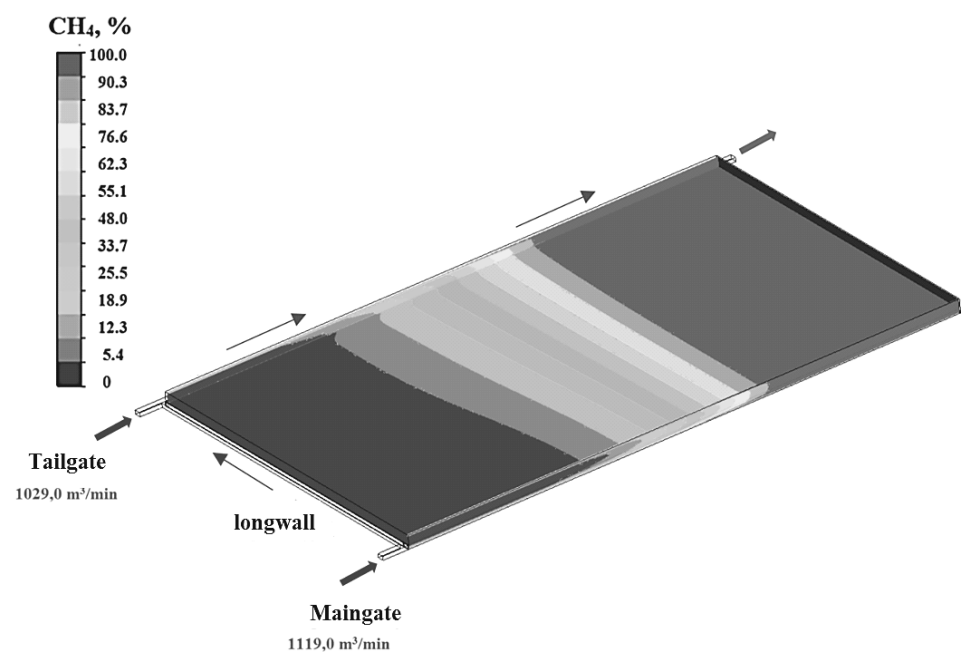

Fig. 4 Distribution of methane concentration in goaf with caving in exploitation longwall 


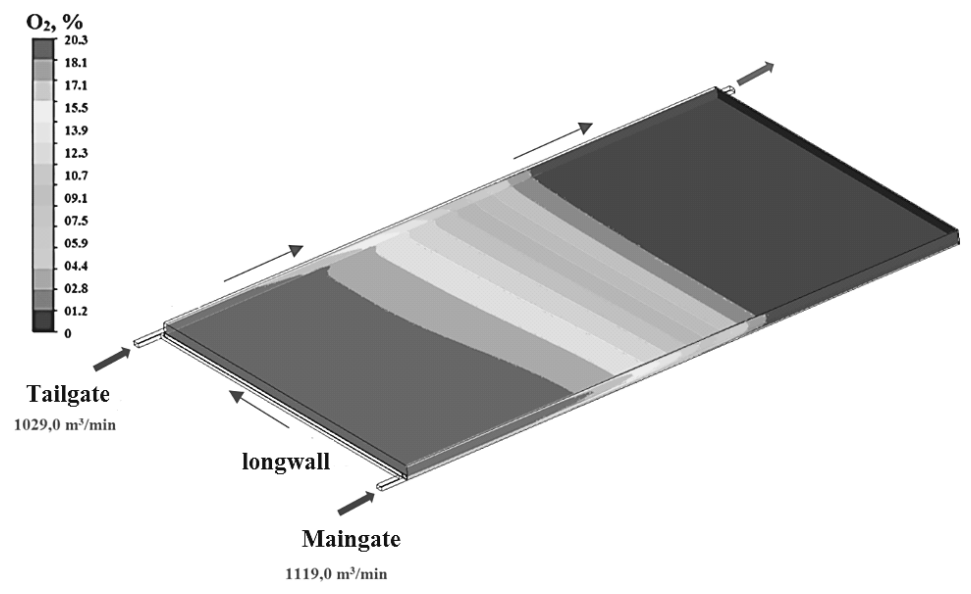

Fig. 5 Distribution of oxygen concentration in goaf with caving in exploitation longwall

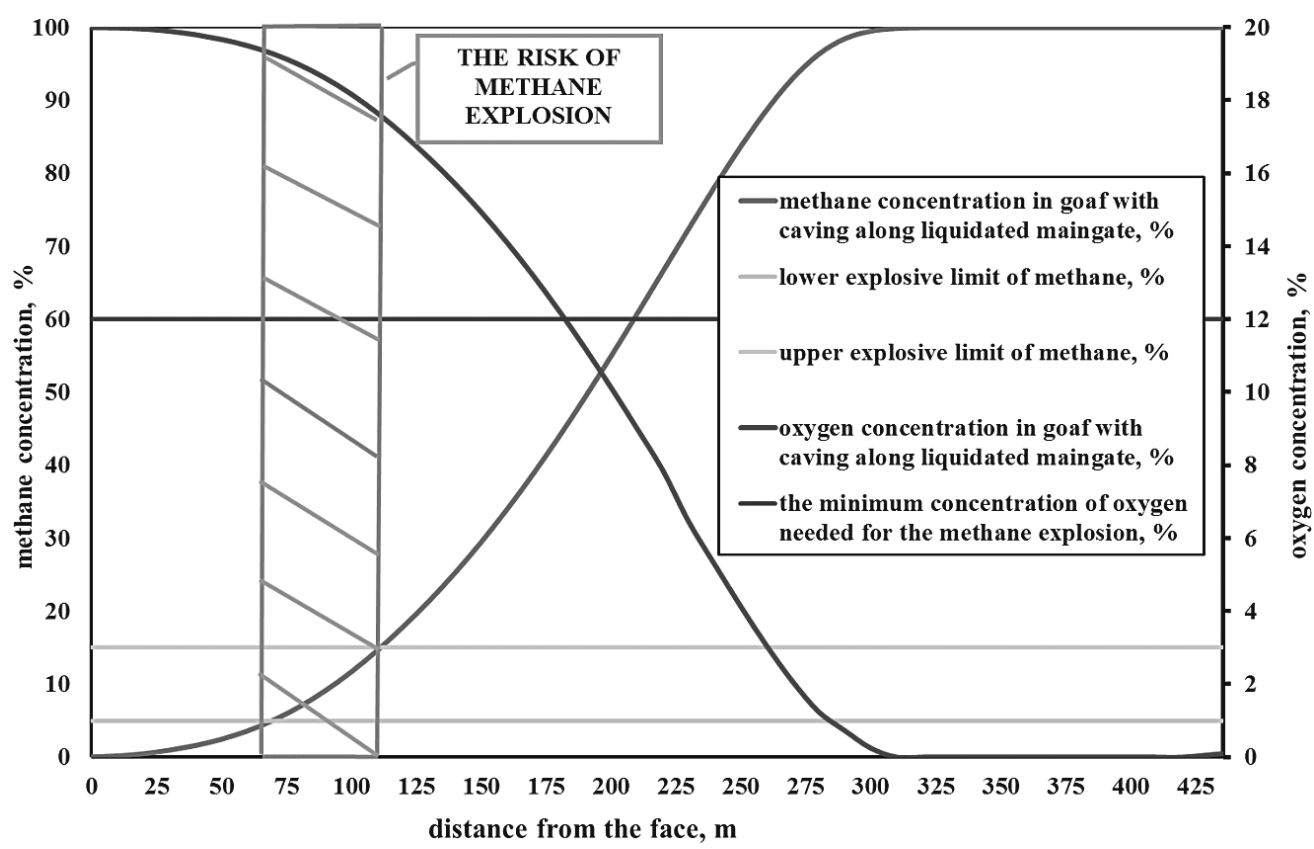

Fig. 6 Characteristics of methane and oxygen concentration in goaf with caving along liquided longwall maingates

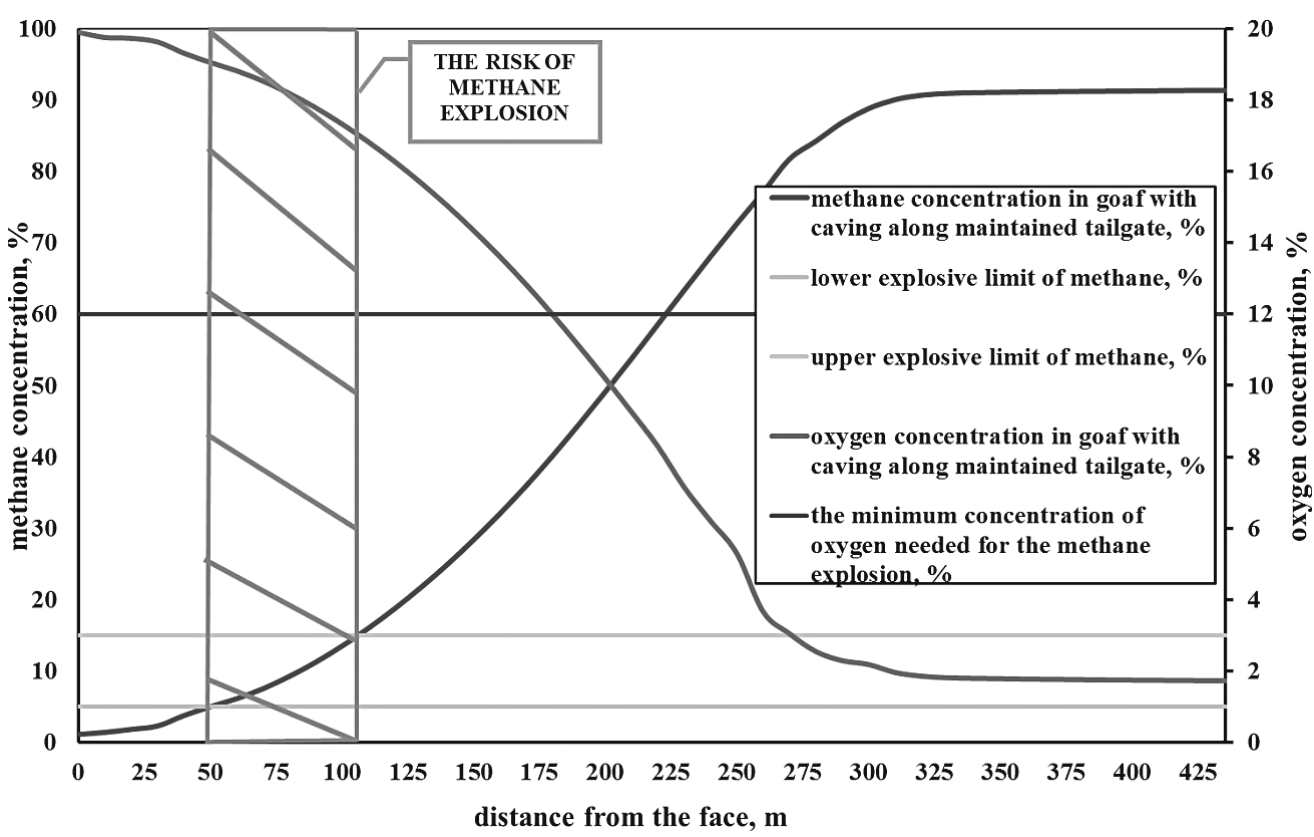

Fig. 7 Characteristics of methane and oxygen concentration in goaf with caving along maintained longwall tailgates 
In Figure 6, there is presented characteristics of methane and oxygen concentration along liquidated longwall maingates in goaf, and in Figure 7 - distribution of methane and oxygen concentration along maintained longwall tailgatels in goaf.

Performed analysis showed that methane explosive concentration in the mixture with air, in which the oxygen concentrations equals to minimum $12 \%$ is located at a distance from $69.0 \mathrm{~m}$ to $112.0 \mathrm{~m}$ from the longwall face along the liquidated longwall maingate, and at the distance from $50.0 \mathrm{~m}$ to $115.0 \mathrm{~m}$ from the longwall face along the maintained longwall tailgate.

Higher risk of explosion, from the point of view of its effect on the crew operating in longwall exists in goaf along the maintained tailgate (the area closer to the working area). In this system there is possibility of quick movement of explosion to the operating surface of the longwall.

\section{CONSLUSIONS}

Activation of methane hazard i.e. explosions and inflammation of methane in underground work environment is a major menace to safety of the entire crew and can be cause of many material losses for the mine.

It is very important to determine potential zones, in which such events can be presented. The results of such analyzes could be the base for preventive operation, which aim is to decrease methane concentration in endangered zones or cut off the air supply to it.

Very often, in order to carry out these activities interruptions in exploitation process are presented. However, to have effective preventive actions, it is necessary to accurately determine the location of particularly hazard zones.

Presented in the article, research methodology and obtained results allow to accurately determine the position of zones in the goaf with caving, in which necessary conditions for occurred explosion of methane are fulfilled. However, the credibility of these results largely depends on the results of measurements of the air flow, determined methane content of seam and physical parameters of gobs (e.g. permeability).

Obtained results clearly proof that numerical methods, combined with the results of tests in real (partial) conditions can be successfully used for the analysis of variants of processes related to ventilation of underground mining headings, and also in the analysis of emergency states.

\section{RERERENCES}

[1] Ansys Fluent Theory Guide 14.0, 2011.

[2] K. Kurus and B. Białecka. „Analysis of safety at work rate in chosen mines of Upper Silesian Coal Basin", in Management Systems in Production Engineering, vol. 4(8), 2012, pp. 19-24.

[3] J. Brodny and M. Tutak. „Numerical analysis of airflow and methane emitted from the mine face in a blind dog heading", in Management Systems in Production Engineering, vol. 2(18), 2015, pp. 110-118.

[4] J. Kabiesz et al. Raport roczny o stanie podstawowych zagrożeń naturalnych i technicznych $w$ górnictwie węgla kamiennego, Katowice: Główny Instytut Górnictwa, 2014.

[5] A. Klimanek. "Numerical modelling of natural draft wet-cooling towers", in Archives Computers Methods Engineering, vol. 20(1), 2013, pp. 61-109.

[6] B. Kozłowski. Zagrożenie wyrzutami gazów i skał w górnictwie węglowym, Warszawa-Kraków: Państwowe Wydawnictwo Naukowe, 1980.

[7] J.C. Kurnia, A.P. Sasmito and A.S. Mujumdar. Computational study of thermal management in underground coal mines: effect of operating ventilation parameters, Singapore: National University of Singapore, 2012.

[8] J.C. Kurnia, A.P. Sasmito and A.S. Mujumdar. „CFD simulation of methane dispersion and innovative methane management in underground mining faces", in Applied Mathematical Modelling, vol. 38(14), 2014 pp. 3467-3484.

[9] J.C. Kurnia, A.P. Sasmito and A.S. Mujumdar. „Simulation of a novel intermittent ventilation system for underground mines", in Tunnelling and Underground Space Technology, vol. 42, 2014, pp. 206-215.

[10] M. Tutak. „Numerical analysis of influence of exogenous fire in dog heading on parameters of the air stream flowing through this heading", in Management Systems in Production Engineering, vol. 2(14), 2014, pp. 76-80.

[11] K.K. Veersteg and W. Malalasekera. An Introduction to Computational Fluid Dynamics: The Finite Volume Method, Pearson Education, 2007.

\author{
dr hab. inż. Jarosław Brodny, prof. Pol. Śl. \\ Silesian University of Technology, Faculty of Organisation and Management \\ Institute of Production Engineering \\ ul. Roosevelta 26-28, 41-800 Zabrze, POLAND \\ e-mail: jaroslaw.brodny@polsl.pl \\ mgr inż. Magdalena Tutak \\ Silesian University of Technology, Faculty of Mining and Geology \\ Institute of Mining \\ ul. Akademicka 2, 44-100 Gliwice, POLAND \\ e-mail: magdalena.tutak@polsl.pl
}

